\title{
Improved Detached Leaf Assay for Rapid Screening against Late Leaf Spot in Groundnut
}

\author{
Dnyaneshwar B. Deshmukh ${ }^{1}$, Ashwini M. Teggi ${ }^{2}$, Hari Kishan Sudini ${ }^{2}$, \\ Sunil Chaudhari ${ }^{2}$, Balram Marathi ${ }^{1}$, Ch. V. Durga Rani ${ }^{2}$ and Murali T. Variath ${ }^{2} *$ \\ ${ }^{1}$ Institute of Biotechnology, Professor Jayashankar Telangana State Agricultural University, \\ Rajendranagar, Hyderabad- 500030 \\ ${ }^{2}$ Groundnut Breeding, International Crops Research Institute for the Semi-Arid Tropics \\ (ICRISAT), Patancheru- 502324
}

*Corresponding author

\begin{tabular}{|c|c|}
\hline & A B S T R A C T \\
\hline Keywords & \multirow{4}{*}{$\begin{array}{l}\text { The use of resistant cultivars is the most economical and effective method to control late leaf spot } \\
\text { (Phaeoisariopsis personata) in groundnut. In the process of breeding for host plant resistance, the } \\
\text { plant material is evaluated in the hot spot location under field conditions. But this process of } \\
\text { evaluating the whole crop cycle demands lot of labour and time, the disease expression fluctuates } \\
\text { with environmental conditions. Here, we present the improved detached leaf assay method for } \\
\text { screening groundnut lines under controlled conditions. Three genotypes of groundnut viz., GPBD } 4 \\
\text { ICGV } 13193 \text { and TMV } 2 \text { were screened against late leaf spot. Based on visual observation of } \\
\text { incubation period, percentage of leaf area damaged, lesion diameter, latent period and defoliation } \\
\text { percentage were recorded. The varieties GPBD } 4 \text { and TMV } 2 \text { consistently showed lowest and highest } \\
\text { disease intensities, respectively. While the introgression line ICGV } 13193 \text { showed moderate } \\
\text { resistance. This methodology may allow the detection of sources of resistance that specifically } \\
\text { involve one or more components of resistance for defence mechanisms against LLS. When } \\
\text { combined with field assessment, this methodology should also enable to quantitatively assess the } \\
\text { relative role of each components of resistance to LLS. Therefore, detached leaf assay can be used to } \\
\text { screen groundnut genotypes against late leaf spot. }\end{array}$} \\
\hline $\begin{array}{l}\text { Arachis, Late leaf } \\
\text { spot, Detached leaf } \\
\text { assay, Latent } \\
\text { period, Per cent leaf } \\
\text { area damaged, Host } \\
\text { plant resistance }\end{array}$ & \\
\hline Article Info & \\
\hline $\begin{array}{l}\text { Accepted: } \\
\text { 26 June } 2018 \\
\text { Available Online: } \\
10 \text { July } 2018\end{array}$ & \\
\hline
\end{tabular}

\section{Introduction}

Among biotic constraints that limit groundnut yield, foliar fungal diseases are important globally. Cercospora or tikka leaf spots (early and late leaf spot) are the most important fungal diseases of groundnut. Late leaf spot (LLS) caused by Phaeoisariopsis personata (Berk. and M.A. Curtis) van Arx. is more prevalent during the rainy season in all groundnut-growing areas of India. It starts around mid-August when the fungal spores germinate and penetrate peanut leaves through stomata located on the abaxial surface.

Round-shaped black lesions become visible within 1 week of fungal germination. Since the spores are deposited in the soil, LLS disease usually starts from the bottom layer of the plant canopy and moves upward. As the fungal lesions enlarge, coalescence of lesions is often observed in highly susceptible lines 
(Gill, 2013). Sporulation occurs 20 to 30 days after infection. Secondary infection from freshly produced spores is common in the long peanut growing season. Leaf spot affects by reducing the available photosynthetic area, localized damage of leaf tissues and defoliation. Highly susceptible lines can lose all their leaves one month prior to maturity. The necrotic area and the defoliation induced by LLS can cause $30-70 \%$ yield penalty in susceptible cultivars (Bourgeois et al., 1991 and Singh et al., 2011).

In resistance breeding program, evaluation for the host resistance needs to be performed with accuracy which is conducted either in greenhouse and/or field conditions using whole seedlings or adult plants screening, respectively. Field screening can be conducted only during crop season and there will be masking effect of one gene over other.

Moreover, the fluctuating environmental conditions, especially temperature and humidity, greatly influence the disease progress. In field environment, different unrelated pathogens and/or various races of the same pathogen may co-infect the plants, which can complicate the assessment procedure.

The alternative to field-based assessment is to carry out evaluation in a controlled environment (laboratory experiments) where whole-plant screening can be done. However, whole-plant screening also has its limitations, including a requirement for a spacious controlled environment glasshouse and also requires relatively high bulks of inoculum. So, a screening technique mitigating the constraints of seedling and adult plant screening is required during pre-breeding of resistant varieties. The advanced detached plant part screening assay allows better control over temperature and humidity, and the use of larger number of replicates with lesser quantity of inoculum and can retain the healthy plant for further studies.

Detached plant part screening assay, a rapid screening technique that screens materials under controlled condition has been used in many crops. Detached leaves have been used to screen plant material against many diseases like early leaf spot of groundnut (Ricker et al., 1985), anthracnose in white beans ( $\mathrm{Tu}, 1986)$, Colletotrichum of Arabidopsis (Liu et al., 2007), crown rust of oat (Jackson et al., 2008), late leaf spot of groundnut (Janila et al., 2013), powdery mildew in pea (Azmat et al., 2013), leaf rust of wheat (Boydom et al., 2013) and Net Blotch of Barley (El-Mor et al., 2018)

The objective of this study was to examine the feasibility of using improved detached leaf assay for disease reaction assessment of breeding lines. Our approach was to compare results for inoculated detached leaves of different crop growth stages.

\section{Materials and Methods}

\section{Plant material for detached leaf assay}

The genotypes viz., GPBD 4 (resistant check), ICGV 13193 (moderate resistant) and a susceptible control TMV 2 were selected for the late leaf spot screening study. Seeds of these genotypes were sown in field condition in the experimental plots of Alfisols (AlfisolPatancheru Soil Series; UdicRhodustolf) at ICRISAT, Patancheru, India (at $17.53^{\circ} \mathrm{N}$ latitude and $78.27^{\circ}$ E, 545 m.a.s.l.) during post-rainy season of 2018. The fully expanded quadrifoliate leaves (third or fourth from top) from 45 and 70 days old plants were excised through pulvinus and screened for LLS resistance in two separate experiments designated as set 1 and set 2 respectively. The excised leaves were washed with deionised water and used as an explant. 
Experimental design, screening techniques, data recording and analysis

Each test was carried out in two replicates in a Complete Randomized Design (CRD). The mixture of sand: vermiculite mixture $(1: 1 \mathrm{v} / \mathrm{v})$ was prepared and steam sterilized at $15 \mathrm{lbs}$ pressure and $121^{\circ} \mathrm{C}$ for $1 \mathrm{~h}$ in two cycles of autoclave. The excised explants from all three genotypes were planted in sterile culture (1.5 $\mathrm{cm}$ thick sand) in plastic trays $(40 \times 30 \mathrm{~cm})$ and transferred to dew chamber. Immediately after planting the detached leaves in the tray were sprayed with LLS inoculum $(30,000$ conidia $\mathrm{ml}^{-1}$ ). The dew chamber conditions were maintained at a temperature of $24^{0} \mathrm{C}$ and $85 \%$ relative humidity. Further the trays were covered with transparent plastic sheets to maintain suitable conditions for disease development. Water was sprayed on the culture, leaves and the sheets once daily up to 8 days. Disease development was monitored every alternate day from 5 to 40 days after inoculation (DAI). The following parameters were studied for the components of resistance and histological parameters.

\section{Components of resistance to LLS}

Data on the following parameters were recorded:

1. The incubation period (IP): IP is defined as days from inoculation to appearance of the first lesion. It is recorded on each leaf every alternate day from 5 days to 40 DAI.

2. Latent period (LP): LP is defined as days from inoculation to the appearance of the first sporulating lesion. It is recorded on each leaf every alternate day from 5 to 40 DAI.

3. Leaf area damage (LAD): The percent LAD was assessed by comparing the leaves with diagrams depicting leaves with known percentage of their areas affected. It was measured at $40 \mathrm{DAI}$.

4. Lesion diameter (LD): $\mathrm{LD}$ is the average diameter of five randomly selected lesions on each leaflet. It was measured at 40 DAI using vernier caliper under $20 \times$ magnifying lens and the data was recorded in $\mathrm{mm}$.

5. Defoliation percentage (DP): Percent leaf defoliation and disease scores were recorded at 40 DAI. The percent defoliation was calculated based on the total number of leaves and number of leaves defoliated.

The disease score for LLS were recorded at 20 and 40 DAI, referring modified 1-9 scale, as given by Subrahmanyam et al., (1995). For detached leaf assay, the results were differentiated on the basis of appearance of symptoms and symptom-free leaflets. All the statistical tests and parameters were conducted using Microsoft Excel (version, 2016).

\section{Results and Discussion}

The results on screening of fully expanded excised quadrifoliate leaves provided a clearcut differentiation between susceptible, resistant and moderately resistant cultivars based on artificial inoculations with spore concentration higher than 30,000 conidia $\mathrm{ml}^{-1}$. Since disease severity in the susceptible cultivar increased with duration, the differentiation became more evident. The modified composition of culture medium with mixture of sand:vermiculite mixture $(1: 1 \mathrm{v} / \mathrm{v})$ enabled maintenance of optimum moisture and humidity $(85 \%)$ with minimum contamination of saprophytes and other fungus.

The experimental results of Set 1 and Set 2 are presented in Table 1 and 2, respectively. This showed that the disease severity and incidence 
were generally not affected by leaflet age; and the appearance of black spores on the except in the case of percent leaf defoliation. centre of necrotic lesion was recorded as latent The infection was identified by dark necrotic period. spots to the area of the abaxial surface of leaf

Table.1 Response of groundnut genotypes to late leaf spot screening using detached leaf assay under controlled conditions in two independent experiments at 45 and 70 days old crop stage

\begin{tabular}{|l|c|c|c|c|c|c|c|}
\hline \multicolumn{7}{|c|}{ Set 1: Dew chamber experiment at 45 days old excised leaves } \\
\hline & IP & LP & LLS_20 DAI & LLS_40 DAI & \% LAD & LD (mm) & \% LDF \\
\hline GPBD 4 & 16.5 & 19.5 & 2.5 & 3.0 & 6.0 & 1.4 & 6.0 \\
\hline TMV 2 & 7.5 & 13.0 & 6.5 & 8.5 & 62.5 & 4.6 & 67.5 \\
\hline ICGV 13193 & 12.5 & 17.0 & 3.0 & 4.0 & 22.5 & 2.2 & 17.5 \\
\hline Sem ( \pm ) & 0.6 & 0.3 & 0.3 & 0.3 & 2.6 & 0.1 & 2.6 \\
\hline LSD 5\% & 3.5 & 1.8 & 1.8 & 1.8 & 15.6 & 0.7 & 15.6 \\
\hline
\end{tabular}

\begin{tabular}{|l|c|c|c|c|c|c|c|}
\hline \multicolumn{7}{|c|}{ Set 2: Dew chamber experiment at 45 days old excised leaves } \\
\hline & IP & LP & LLS_20 DAI & LLS_40 DAI & \% LAD & LD (mm) & \%LDF \\
\hline GPBD 4 & 15.5 & 19.5 & 2.5 & 3.5 & 9.0 & 1.4 & 7.0 \\
\hline TMV 2 & 8.5 & 13.0 & 7.5 & 9.0 & 70.0 & 4.8 & 75.0 \\
\hline ICGV 13193 & 13.5 & 17.5 & 3.0 & 4.0 & 22.5 & 2.0 & 19.0 \\
\hline Sem ( \pm ) & 0.6 & 0.3 & 0.8 & 0.3 & 2.5 & 0.1 & 3.1 \\
\hline LSD 5\% & 3.5 & 1.8 & 4.6 & 1.8 & 11.0 & 0.5 & 18.6 \\
\hline
\end{tabular}

IP: Incubation period, LP: latent period, LLS_20 DAI: LLS score at 20 days after inoculation, LLS_40 DAI: LLS score at 40 days after inoculation, \% LAD: Per cent leaf area damaged by LLS, LD: Lesion diameter (mm), \% LDF: Per cent leaf defoliation

Fig.1 Pooled mean of experiment Set 1 and Set 2. (1) Incubation period in days, (2) latent period in days, (3) late leaf spot score at 20 DAI, (4) late leaf spot score at 40 DAI, (5) percent leaf area damaged, (6) lesion diameter in $\mathrm{mm}$, and (7) percent leaf defoliation

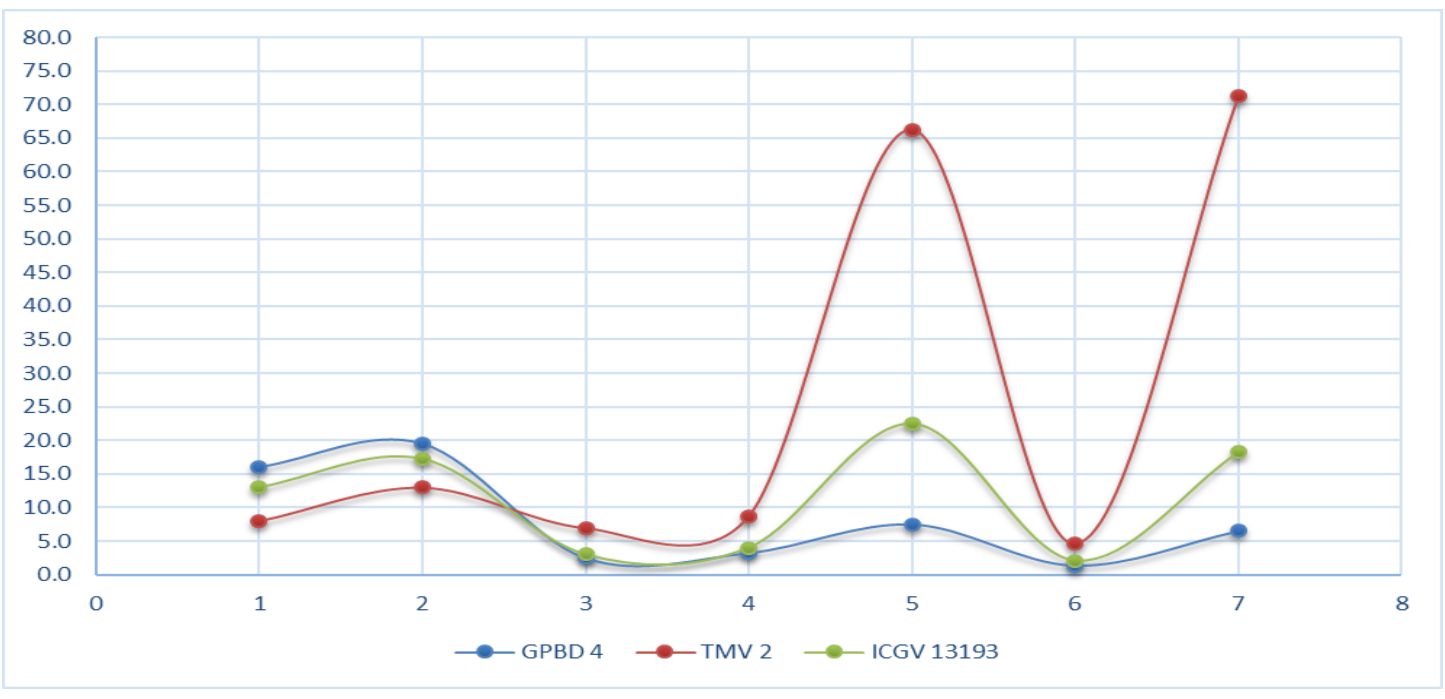


Across three groundnut genotypes in the two experimental sets, the mean incubation and latent periods (Fig. 1) were longest in resistant cultivar GPBD 4 (16 and 19.5 DAI), moderate in ICGV 13193 (13 and 17.3 DAI) and shortest in susceptible cultivar ( 8 and 13 DAI) at $24^{\circ} \mathrm{C}$ and $85 \%$ relative humidity. The mean disease score of resistant check GPBD 4 was 2.5 and 3.3, while that of susceptible cultivar TMV 2 was 7.0 and 8.75 at 20 and 40 DAI, respectively. The cultivar ICGV 13193 had mean scores of 3 and 4 at 20 and 40 DAI, respectively and was graded as moderately resistant. The resistant cultivar GPBD 4 showed smaller lesion diameter (LD) of $1.4 \mathrm{~mm}$. The moderately resistant cultivar ICGV 13193 measured $2.1 \mathrm{~mm}$ LD and the susceptible cultivar TMV 2 showed largest lesions with $4.7 \mathrm{~mm}$ LD.

The cultivar TMV 2 was severely infected with LLS exhibiting $66.3 \%$ percent leaf area damage (LAD) and the genotype ICGV 13193 was moderately infected with $22.5 \%$ LAD. The resistant genotype, GPDB 4 showed least damaged area accounting only 7.5\% LAD. Percent leaf defoliation (\% LDF) was the most variable parameter with least defoliation in GPBD 4 (6.5\%), moderate defoliation in ICGV 13193 (18.3) and maximum in TMV 2 (18.2\%).

The cultivar TMV 2 was severely infected with percent leaf area damaged (LAD) of $66.3 \%$ and line ICGV 13193 was moderately infected with $22.5 \%$ LAD. The resistant genotype, GPDB 4 showed least damage due to LLS with only $7.5 \%$ LAD. Percent leaf defoliation (\% LDF) was the most variable parameter with least defoliation in GPBD 4 (6.5\%), moderate defoliation in ICGV 13193 $(18.3 \%)$ and maximum in TMV $2(18.2 \%)$.

The results also showed that leaflets taken from different growth stages of plants responded similarly to inoculation as they were excised immediately after being fully expanded. The well-known resistant check, GPBD 4 showed clear resistance to LLS fungus in both the experiments while susceptible cultivar, TMV 2 was severely affected with leaf spot. The cultivar ICGV 13193 exhibited moderate resistance with a mean score of 4 in both the screening assay.

Detached leaf culture was originally described by Subrahmanyam et al., (1990) as a bioassay for obligate leaf pathogens. The current study examined the feasibility of using modified detached leaflet assay for disease assessment in late leaf spot of groundnut. In earlier studies, either sand culture (Janila et al., 2013) or whole plant assay (Dwivedi et al., 2002) was used to screen detached leaf against LLS. But the inclusion of of sand:vermiculite mixture $(1: 1 \mathrm{v} / \mathrm{v})$ enabled to maintain higher humidity and proper moisture in the medium with secondary infection. The disease reaction of leaflets inoculated with artificial inoculum is determined using both disease incidence and severity values, was generally similar to the reaction of the intact plant (Dwivedi et al., 2002).

The ability to quickly screen breeding lines for resistance is often limited by the amount of controlled environment space for the required number of plant lines and pathogen isolates. Low standard errors for each evaluation method set 1 and set 2 further confirm the consistency of the disease response ratings between the detached leaf. This showed that the disease severity and incidence were generally not affected by leaflet age; the exceptions to this were results for both parameters of percent leaf defoliation. Defoliation may occur due to the severe fungal infection at leaf node and further resulted in physiological senesce. Other workers using detached leaves have also reported that the cultivar GPBD 4 is resistant to LLS while TMV 2 is highly 
susceptible to LLS (Dwivedi et al., 2002 and Janila et al., 2013). There are several advantages with the excised leaf method: (a) a plant can be used to screen for different races of a pathogen, (b) seeds of a partially resistant plant with favourable agronomic characteristics can be saved for future breeding purposes, (c) if resistance to different races of a pathogen involves two or more genes, the genetic composition of each segregating progeny of a cross can be determined, and (d) assay can be suitable in histo-pathological studies of plant.

With this method, a plant can be screened many times because screening can be done at any growth stage while they are grown in the field or in the greenhouse without affecting their growth and seed production. This method offers considerable time saving in breeding for resistance. It works well on the newly expanded leaves because they appear to have less contamination with other foliar organisms. This method would be valuable for evaluating groundnut for resistance to late leaf spot when limited quantities of seed are available in early generation breeding material and the experiment cannot be conducted in replication, e.g., $F_{1}, F_{2}$ seeds.

\section{References}

Subrahmanyam P, Wongkaew S, Reddy DVR, Demski JW, McDonald D, Sharma SB, Smith DH, Nigam SN, and Sudini H. 2012. Field diagnosis of groundnut diseases. Information Bulletin no. 36 (revised). (in En. Fr. Summaries in En, Fr, Es.) Patancheru, A.P. 502 324, India: International Crops Research Institute for the SemiArid Tropics. 88 pp. ISBN 92-9066255-7.

Bourgeois, G., K.J. Boote, and R.D. Berger. 1991. Growth, development, yield, and seed quality of Florunner peanut affected by late leafspot. Peanut Sci. 18:137-143.

Singh, M. P., Erickson, J. E., Boote, K. J., Tillman, B. J., Jones, J. W., and van Bruggen, A. H. C. 2011. Late leaf spot effects on growth, photosynthesis, and yield in peanut cultivars of differing resistance. Agron. J. 103, 85-91. doi: 10.2134/agronj2010.0322.

Butler, D.R., Wadia, K.D.R. and Jadhav, D.R. 1994. Effects of leaf wetness and temperature on late leaf-spot infection of groundnut. Plant Pathology, 43(1), 112-120.

Ricker, M.D., Beute, M.K. and Campbell, C.L. 1985. Components of resistance in peanut to Cercospora arachidicola. Plant Disease, 69(12), 1059-1064.

Tu, J.C. 1986. A detached leaf technique for screening beans (Phaseolus vulgaris L.) in vitro against anthracnose (Colletotrichum lindemuthianum). Canadian journal of plant science, 66(3), 805-809.

Liu, G., Kennedy, R., Greenshields, D.L., Peng, G., Forseille, L., Selvaraj, G. and Wei, Y. 2007. Detached and attached Arabidopsis leaf assays reveal distinctive defense responses against hemibiotrophic Colletotrichum spp. Molecular Plant-Microbe Interactions, 20(10), 1308-1319.

Jackson, E.W., Obert, D.E., Chong, J., Avant, J.B. and Bonman, J.M., 2008. Detached-leaf method for propagating Puccinia coronata and assessing crown rust resistance in oat. Plant disease, 92(10), 1400-1406.

Pasupuleti, J., Ramaiah, V., Rathore, A., Rupakula, A., Reddy, R.K., Waliyar, F. and Nigam, S.N. 2013. Genetic analysis of resistance to late leaf spot in interspecific groundnuts. Euphytica, 193(1), 13-25.

Azmat, M.A., Khan, A.A., Cheema, H.M.N., Ashraf, M. and Niaz, S. 2013. 
Detached leaf assay coupled with microscopic conidial quantification: an efficient screening method for powdery mildew resistance in pea. Int. J. Agric. Biol, 15, 957-962.

Boydom, A. and Dawit, W., 2013. Evaluation of detached leaf assay for assessing leaf rust (Puccinia triticina Eriks.) resistance in wheat. Journal of Plant Pathology and Microbiology.

El-Mor, I.M., Fowler, R.A., Platz, G.J., Sutherland, M.W. and Martin, A. 2018. An Improved Detached-Leaf Assay for Phenotyping Net Blotch of Barley Caused by Pyrenophora teres. Plant Disease, 102(4), 760-763.

Subrahmanyam, P., McDonald, D., Waliyar, F., Reddy, L. J., Nigam, S, N., Gibbons, R, W., Rao, V. R., Singh, A.
K., Pande, S., Reddy, P. M., and Subbarao, P. V. 1995. Screening methods and sources of resistance to rust and late leaf spot of groundnut Information Bulletin no 47 ICRISAT, Patancheru, India: 24p.

Subrahmanyan, P., P. M. Reddy, and D. McDonald. 1990. Parasitism of rust, early and late leafspot pathogens of peanut by Verticillium lecanii. Peanut Sci. 17:1-3.

Dwivedi, S.L., Pande, S., Rao, J.N. and Nigam, S.N. 2002. Components of resistance to late leaf spot and rust among interspecific derivatives and their significance in a foliar disease resistance breeding in groundnut (Arachis hypogaea L.). Euphytica, 125(1), 81-88.

\section{How to cite this article:}

Dnyaneshwar B. Deshmukh, Ashwini M. Teggi, Hari Kishan Sudini, Sunil Chaudhari, Balram Marathi, Ch. V. Durga Rani and Murali T. Variath. 2018. Improved Detached Leaf Assay for Rapid Screening against Late Leaf Spot in Groundnut. Int.J.Curr.Microbiol.App.Sci. 7(07): 3987-3993. doi: https://doi.org/10.20546/ijcmas.2018.707.464 